\title{
Factors Associated with Serious Injuries among Adolescents in Ghana: Findings from 2012 Global School Health Survey
}

\author{
Martin Ackah $\mathbb{D}^{1},{ }^{1}$ Mohammed Gazali Salifu $\mathbb{D}^{2},{ }^{2}$ and Hosea Boakye $\mathbb{D}^{3}$ \\ ${ }^{1}$ Physiotherapy Department, Korle Bu Teaching Hospital-Ghana, Accra, Ghana \\ ${ }^{2}$ Ministry of Health, Accra, Ghana \\ ${ }^{3}$ Physiotherapy Department, LEKMA Hospital-Ghana, Accra, Ghana \\ Correspondence should be addressed to Martin Ackah; martinackah10@gmail.com
}

Received 16 December 2020; Revised 18 January 2021; Accepted 2 February 2021; Published 20 April 2021

Academic Editor: Carlo Eduardo Medina-Solis

Copyright ( $) 2021$ Martin Ackah et al. This is an open access article distributed under the Creative Commons Attribution License, which permits unrestricted use, distribution, and reproduction in any medium, provided the original work is properly cited.

Introduction. Injuries are of public health concern and the leading cause of residual disability and death among teenagers, especially in low- and middle-income countries (LMICs). In Ghana, the burden of injury among adolescents is under-reported. Hence, the study sought to determine the prevalence of serious injuries (SI) and the potential factors influencing these injuries among school children in Ghana. Methods. This study was conducted in Ghana among Junior High School (JHS) and senior high school students (SHS) using the 2012 Global School-Based Student Health Survey (GSHS) data. The GSHS employed two-stage cluster sampling method. Serious injuries (SI) and independent factors were measured via self-administered questionnaires. Pearson chi-square test between each explanatory variable and serious injuries was conducted and the level of statistical significance was set at $5 \%$. The significant variables from the chi-square test were selected for multiple logistic regression analysis. Multiple logistic regression was performed to estimate the adjusted odds ratio (AOR) at 95\% confidence interval (CI). Results. The prevalence of SI in the past 12 months was 66\% [CI=61.8-70.2]. The most common cause of SI was fall, 36\%. The common types of injuries were cut/stab wounds and broken/dislocated bone. In the multiple logistic regression analysis, after controlling for other variables, educational level $(\mathrm{AOR}=0.64, \mathrm{CI}=0.44-0.90, p<0.015)$, suicidal ideation $(\mathrm{AOR}=1.58, \mathrm{CI}=1.00-2.48, p<0.002)$, suicidal attempt $(\mathrm{AOR}=1.88, \mathrm{CI}=1.29-2.72, p<0.001)$, having at least one close friend $(\mathrm{AOR}=1.49, \mathrm{CI}=1.17-1.89, p<0.002)$, school truancy $(\mathrm{AOR}=1.66, \mathrm{CI}=1.31-2.09, p<0.000)$, smoking marijuana $(\mathrm{AOR}=2.64, \mathrm{CI}=1.22-5.69)$, and amphetamine use $(\mathrm{AOR}=2.95, \mathrm{CI}=1.46-5.69)$ were independently associated with SI. Conclusion. The findings of the study established a high prevalence of SI among adolescents in Ghana, with cut/stab wound and broken/dislocated bone being the most reported type of injuries. This study also revealed that factors such as educational level, suicidal ideation, suicidal attempt, at least one close friend, school truancy, smoking marijuana, and amphetamine use are associated with SI among the adolescents. Therefore, pragmatic interventional programs should be targeted at these factors to curb the rate of SI among junior and senior school students.

\section{Introduction}

Globally, injuries are of public health concern and the leading cause of residual disability and death among those under 19 years, especially in low- and middle-income countries [1]. Global burden of disease estimated that 5.1 million deaths occurred from injuries in 2010, of which $12 \%$ are attributed to unintentional injuries among children and adolescents [2]. In sub-Saharan African (SSA), 250 million people are aged 10-19 years and this number is expected to increase by $24 \%$ by 2020 [3]; however, less attention is paid to adolescent injuries largely due to the greater attention devoted to widespread nutrition deficiencies and communicable diseases [4]. The estimated incidence of injuries for children is 53.1/100000 in SSA [4]. In addition, all injuryrelated mortalities occur globally, more than $95 \%$ occur in low- and middle-income countries with detrimental physical, psychological, and economic effects [5].

Prior epidemiological studies have indicated that injuries among adolescents have declined by $50 \%$ in developed countries such as Britain, US, Austria, and Canada over the past 30 years through "multisectored approach" to 
prevention $[1,6]$. For instance, the prevalence of injury was approximately $21 \%$ in Europe [7], 24\% in Canada [8], and $38 \%$ in China [9]. In low-income countries, such studies are mostly limited to hospital and community-based information [1] and the prevalence is relatively higher. For example, the prevalence of injuries was 62\% in Ethiopia [5] and 73.6\% in Nigeria [10].

In Ghana, the burden of injuries among adolescents is not well described even though it is hypothesized to be higher based on data in other LMICs. However, Gyedu et al. [11] observed that household child injury (HCI) burden in Ghana is about ten times higher than that reported from the United States [12]. In addition, factors influencing serious injuries such as psychological, personal, and school environment factors have not been extensively studied among these targeted populations (adolescents attending school).

Therefore, this study sought to assess and determine the prevalence of SI and its potential influencing factors among adolescents attending school in Ghana. This will aid in the development of preventive and monitoring strategies against serious injuries among adolescents in Ghana.

\section{Methods and Materials}

2.1. Study Design. The researchers utilized data from the 2012 Global School-Based Student Health Survey (GSHS), Ghana version [13]. The GSHS is a school-based survey which uses a self-administered questionnaire. The survey obtained data on health behavior and risk factors associated with the principal cause of death and mortality among school children and young-adults globally. The GSHS was carried out by the WHO with assistance from Disease Control and Prevention (CDC), Middle Tennessee State University, and the Ghana Education Service (GES). The data were obtained using a cross-sectional survey design among WHO countries which were concerned in assessing the behavioral risk factors and protective factors among junior and senior high school students.

2.2. Ethical Consideration. The questionnaire was piloted before the actual data collection to ensure sufficient understanding of the survey items. The survey was approved at Middle Tennessee State University by Institutional Review Board. All ethical considerations and policies from Ghana Education Service (GES) were strictly adhered to during the survey. Permissions were also obtained from GES, heads of the selected schools, and classroom teachers. Both verbal and written assents were obtained from all the students. For minors, assent was obtained from their parents as well. The dataset is freely available for download at http://www.who. int/chp/gshs/en/.

2.3. Sampling. The participants were students from JHS and SHS in Ghana. A two-stage cluster sample design was used to obtain representative information of all the students in the selected schools across the country. During the first stage, schools were selected with probability proportional to enrollment size. At the second stage, classes were randomly selected and all students in the selected classes qualified to partake in the study. The overall response rate was $82 \%$ and $74 \%$ for JHS and SHS, respectively.

2.4. Variables. Outcome variable: the main dependent variable was the prevalence of SI among the participants. It was ascertained by a single question, "during the past 12 months, how many times were you seriously injured?" The options ranged from zero (0) times to twelve (12) or more times. The current study further dichotomized the responses. Those with zero injury were grouped as "no injury" and coded as 0 and those with at least one or more injuries as "serious injuries" coded as 1.

Explanatory variables: these variables were broadly grouped into socio-demographic factors (sex, education, age, hunger, and number of friends), psychological factors (suicidal ideation, planning, and attempt), and personal attributes (truancy, amphetamine, marijuana smoking, and alcohol use]. Explanatory variables are as shown in Table 1.

2.5. Data Analysis. In all analyses, sample weights were applied in order to make it generalizable to the population and further minimize bias on various trends of nonresponses. Some variables were recoded on binary scale in this study as in other existing GSHS study [14-16]. Participants aged 11 years and below were dropped from the analysis. The primary analyzes were carried out in two steps to evaluate variables that were strongly associated with SI among adolescents in Ghana. First, bivariable analyzes using Pearson chi-square were used to investigate potential relationship between the explanatory variables and SI. Variables that showed significant association $(p<0.05)$ were entered into a binary logistic regression model in the second step. Furthermore, multiple logistic regression analyses were used to assess the explanatory variables that independently predict the outcome variable (SI). The results from the multiple logistic regression analyzes were presented as adjusted odds ratio at $95 \%$ confidence interval (CI). $p$ values less than 0.05 were interpreted as significant in all analyzes.

Missingness was addressed using the multiple imputation (MI) technique. The technique was applied to variables where the missing values exceed 5\%. The missing data ranged from $5 \%$ to $11 \%$. The items were missing at random (MAR). The primary sampling unit (PSU), strata, and weight were included in the imputation process as a result of the complex survey design employed during the data collection. MI was used to construct and analyze 5 multiply imputed datasets. The parameter of interest (i.e., serious injuries, amphetamine, and current smoker (marijuana)) were estimated in each imputed dataset separately and combined using Rubin's rule [17]. Imputed values compared reasonably to observed values and results using the complete case analysis which were similar to $\mathrm{MI}$.

The final model goodness of fits was checked [18] using the command "syvlogitgof." The results revealed no evidence of a lack of fit with our model in significantly predicting serious injuries. 
TABLE 1: Explanatory variables data derivation from the survey.

\begin{tabular}{|c|c|c|}
\hline Variable & Survey question & Coding \\
\hline Age & How old are you? & $\begin{array}{c}0=12-14 \text { yrs } \\
1=15-17 \\
2 \geq 18 \text { yrs. }\end{array}$ \\
\hline Sex & What is your sex? & $\begin{array}{l}1=\text { male } \\
2=\text { female }\end{array}$ \\
\hline Educational level & In what grade are you? & $\begin{array}{l}0=\mathrm{JHS} \\
1=\mathrm{SHS}\end{array}$ \\
\hline Hunger & $\begin{array}{c}\text { Students who went hungry most of the time or always because there was not enough food in } \\
\text { their home during the past } 30 \text { days }\end{array}$ & $\begin{array}{l}\text { Yes }=1 \\
\text { No }=2\end{array}$ \\
\hline Close friends & How many close friends do you have? & $\begin{array}{l}0 \text { friend }=1 \\
\geq 1 \text { friend }=2\end{array}$ \\
\hline Suicidal ideation & During the past 12 months, did you ever seriously consider attempting suicide? & $\begin{array}{l}\text { Yes }=1 \\
\text { No }=2\end{array}$ \\
\hline Suicidal plan & During the past 12 months, did you make a plan about how you would attempt suicide? & $\begin{array}{l}\text { Yes }=1 \\
\mathrm{No}=2\end{array}$ \\
\hline Suicidal attempt & During the past 12 months, how many times did you actually attempt suicide? & $\begin{array}{l}1=0 \text { times } \\
2=\geq 1 \text { time }\end{array}$ \\
\hline School truancy & During the past 30 days, how many days did you miss classes or school without permission? & $\begin{array}{l}1=\geq 1 \text { day }(s) \\
2=0 \text { day }\end{array}$ \\
\hline Amphetamine use & $\begin{array}{c}\text { During your life, how many times have you used amphetamine or methamphetamine (also } \\
\text { called ice or yellow) }\end{array}$ & $\begin{array}{l}1=\geq 1 \text { time }(\mathrm{s}) \\
2=0 \text { time }\end{array}$ \\
\hline Current use of alcohol & During the past 30 days, how many days did you have at least one drink containing alcohol? & $\begin{array}{c}1=0 \text { day } \\
2=\geq 1 \text { day }(s)\end{array}$ \\
\hline $\begin{array}{l}\text { Current use of } \\
\text { marijuana }\end{array}$ & $\begin{array}{c}\text { During the past } 30 \text { days, how many times have you used marijuana (also called wee, jah, Indian } \\
\text { hemp, ahabammono, and ganja)? }\end{array}$ & $\begin{array}{l}1=0 \text { times } \\
2=\geq 1 \text { time }\end{array}$ \\
\hline
\end{tabular}

All analyzes were carried out with STATA (Stata Statistical Software: Release 16; College Station, TX; Stata Corp LP) software and Microsoft Office 2013.

\section{Results}

3.1. Background Characteristics of the Adolescents in Ghana. Out of the 3592 adolescents attending school, 53.3\% were males and $43.1 \%$ were aged between 15 and 17 years. Using hunger as a proxy to socio-economic status, $14 \%$ went hungry for the past 30 days. The prevalence of suicidal ideation, suicidal planning, and suicidal attempts was $18.9 \%$, $22.4 \%$, and $24.7 \%$, respectively (Table 2). The prevalence of serious injuries $(\mathrm{SI})$ was $66 \%(\mathrm{CI}=61.8-70.2)$ in the current study (Figure 1). Amphetamine, current drinker (alcohol), and current smoker (marijuana) were 6.5\%, 12.9\%, and $5.0 \%$, respectively. Figure 2 shows the pattern of injuries among the participants; of those who had serious injuries, majority were cut/stab wound $14.9 \%(\mathrm{CI}=13.4-16.5)$, followed by broken bone/dislocated joint $11.5 \%$ $(\mathrm{CI}=9.6-13.9)$, concussion/head injury 4.5\% (3.6-5.6), bad burn $2.9 \% \quad(\mathrm{CI}=2.3-3.8)$, gunshot wound $1.3 \%$ $(\mathrm{CI}=0.8-2.1)$, and Poisoned $1.0 \%(\mathrm{CI}=0.5-1.9)$. Figure 3 depicts the cause of serious injuries among adolescents in Ghana.

\subsection{Distribution and Chi-Square Analysis of Serious Injuries} across Demographic, Psychological, and Personal Attribute Factors. The findings of the bivariate analysis are presented in Table 3. Socio-demographic factors, educational level, being hungry, and having at least one friend were found to be significantly associated with SI. Sex was not associated with SI $(p>0.05)$. Also, psychological factors such as suicidal ideation, suicidal plan, and suicidal attempts were found to be statistically significant. Finally, school truancy, amphetamine used, and smoking marijuana were also found to be significantly associated with SI.

3.3. Association between the Significant Variables and Serious Injuries. The results of the binary logistic regression analysis are presented in Table 4. Sex was added to the model though it was nonsignificant in the bivariate analysis. After controlling for other variables, educational level $(\mathrm{AOR}=0.64$, $\mathrm{CI}=0.44-0.90, \quad p<0.015)$, suicidal ideation $(\mathrm{AOR}=1.58$, $\mathrm{CI}=1.00-2.48, \quad p<0.002)$, suicidal attempt $(\mathrm{AOR}=1.88$, $\mathrm{CI}=1.29-2.72, \quad p<0.001)$, at least having one close friend $(\mathrm{AOR}=1.49, \quad \mathrm{CI}=1.17-1.89, \quad p<0.002)$, school truancy ( $\mathrm{AOR}=1.66, \mathrm{CI}=1.31-2.09, p<0.000)$, and amphetamine use $(\mathrm{AOR}=2.95, \mathrm{CI}=1.46-5.69)$ added significance to the model.

\section{Discussion}

The current study aimed to determine the prevalence of SI and its determinants among school children in Ghana. The prevalence of SI in this study was reported to be 66 percent. There seems to be a huge disparity in the prevalence of injuries between developed countries and that of SSA. While countries in the SSA report high prevalence of injuries, their counterparts in the developed world have appreciably low prevalence. For instance, the prevalence of injuries was approximately $21 \%$ in Europe [7], 24\% in Canada [8], and 
TABLE 2: Background characteristics of the school-going adolescents in Ghana $(n=3592)$.

\begin{tabular}{|c|c|c|c|}
\hline Factor & Variable & Frequency & Percent (\%) \\
\hline \multicolumn{4}{|l|}{ Demographic factors } \\
\hline \multirow{3}{*}{ Sex } & Male & 1914 & 53.3 \\
\hline & Female & 1641 & 45.7 \\
\hline & Missing & 37 & 1.0 \\
\hline \multirow{3}{*}{ Educational level } & JHS & 1603 & 44.6 \\
\hline & SHS & 1974 & 55.0 \\
\hline & Missing & 15 & 0.4 \\
\hline \multirow{4}{*}{ Age category } & $12-14$ & 842 & 23.4 \\
\hline & $15-17$ & 1549 & 43.1 \\
\hline & $18+$ & 1182 & 32.9 \\
\hline & Missing & 19 & 0.5 \\
\hline \multirow{3}{*}{ Went hungry } & Yes & 503 & 14.0 \\
\hline & No & 3078 & 85.7 \\
\hline & Missing & 11 & 0.3 \\
\hline \multirow{3}{*}{ Close friends } & 0 & 452 & 12.6 \\
\hline & $\geq 1$ & 3098 & 86.2 \\
\hline & Missing & 42 & 1.2 \\
\hline \multicolumn{4}{|l|}{ Mental health factors } \\
\hline \multirow{3}{*}{ Suicide ideation } & Yes & 680 & 18.9 \\
\hline & No & 2870 & 79.9 \\
\hline & Missing & 42 & 1.2 \\
\hline \multirow{3}{*}{ Suicide planning } & Yes & 806 & 22.4 \\
\hline & No & 2694 & 75.0 \\
\hline & Missing & 92 & 2.6 \\
\hline \multirow{3}{*}{ Suicide attempt } & Yes & 887 & 24.7 \\
\hline & No & 2666 & 74.2 \\
\hline & Missing & 39 & 1.1 \\
\hline \multicolumn{4}{|l|}{ Personal attributes } \\
\hline \multirow{3}{*}{ Truancy } & Yes & 1295 & 36.0 \\
\hline & No & 2244 & 62.5 \\
\hline & Missing & 53 & 1.5 \\
\hline \multirow{4}{*}{ Amphetamine use } & Yes & 232 & 6.5 \\
\hline & No & 3072 & 85.5 \\
\hline & Missing & 288 & 8.0 \\
\hline & Yes & 464 & 12.9 \\
\hline \multirow{3}{*}{ Current drinker (alcohol) } & No & 2858 & 79.6 \\
\hline & Missing & 270 & 7.5 \\
\hline & Yes & 181 & 5.0 \\
\hline \multirow[t]{2}{*}{ Current smoker (marijuana) } & No & 3259 & 90.7 \\
\hline & Missing & 152 & 4.2 \\
\hline
\end{tabular}

$38 \%$ in China [9], while that of Nigeria [10] was $74 \%$, Liberia [19] 72\%, and Ethiopia [5] 63\%. The observed disparities could be ascribed to a number of factors. Firstly, there is vast literature on awareness and prevention approaches of injuries in the developed countries but such interventions are scarce in SSA. In addition, according to Salam et al. [20], political commitment towards enactment and implementation of polices are crucial in the prevention of injuries. However, such commitment on the part of political leaders in SSA could be said to be low as compared to that of developed countries.

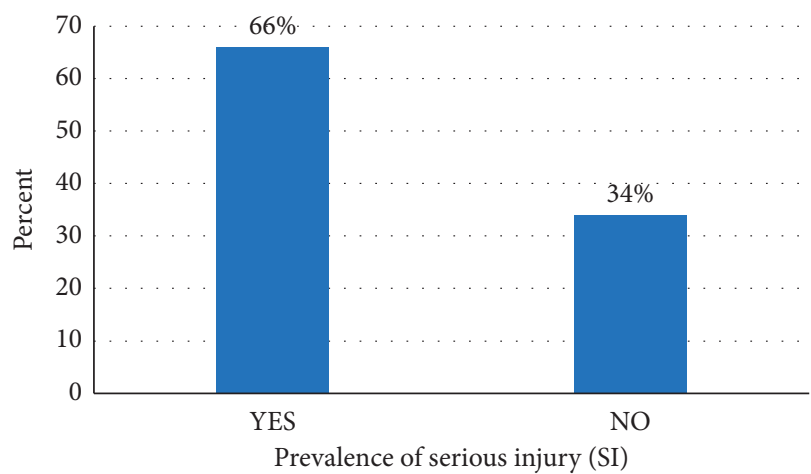

FIGURE 1: Serious injuries among adolescents attending school in Ghana.

With regards to the pattern of injuries, cut/stab wounds and broken/dislocated bones dominated. The findings corroborate with previous studies in four Asian countries [21] and Gao et al. [9] in China, where sprain/ fracture was also found to be dominant among adolescents. Furthermore, fall and motor-vehicle accident were the most common causes of injuries among these populations. This is in agreement with [22-24] and earlier hospital-based and population household-based Ghanaian studies $[11,25]$.

Serious injuries were more prevalent in the female population than male population ( $53 \%$ vs. $51 \%$ ) and had $17 \%$ increased odds of sustaining SI as compared to their male counterpart. However, this was not statistically significant. This is in line with the recent cross-sectional analysis of Liberian adolescents using Global Health School Survey, which also found that sex had no significant association with serious injuries [19]. However, the current findings contradict studies in Palestine [1], Asia [21], and Yemen [23]. The current findings could be ascribed to the fact that majority of the injuries occurred at home where females tend to sustain more injuries as observed by Rommel et al. [26]. In addition, the lack of significant association maybe because intentional injuries were included and tend to affect more to female populations in some contexts.

Hunger as a proxy to socio-economic status was associated with serious injuries among adolescents in Ghana. For example, being hungry was linked with 2.6 increased odds of getting serious injuries as compared to those who were not hungry. This corroborates with Peltzer and Pengpid [27] in Malaysia, four Asian countries (i.e., Indonesia, Sri Lanka, Thailand, and Myanmar) [21], and Canada [28]. In the contrary, Jildeh et al. [1] reported lower prevalence of injuries among adolescents from lower socio-economic family in Palestine. Although socio-economic status has been associated with the development of injuries among children, there are inconsistencies across boundaries in determining which class of social status is more prone to developing injuries. Due to the above, different cultural perceptions of social-economic status could probably account for the inconsistencies.

In other dimensions, senior high school children had a decreased odd of sustaining one or multiple injuries. The possible explanation could be that most second cycle 


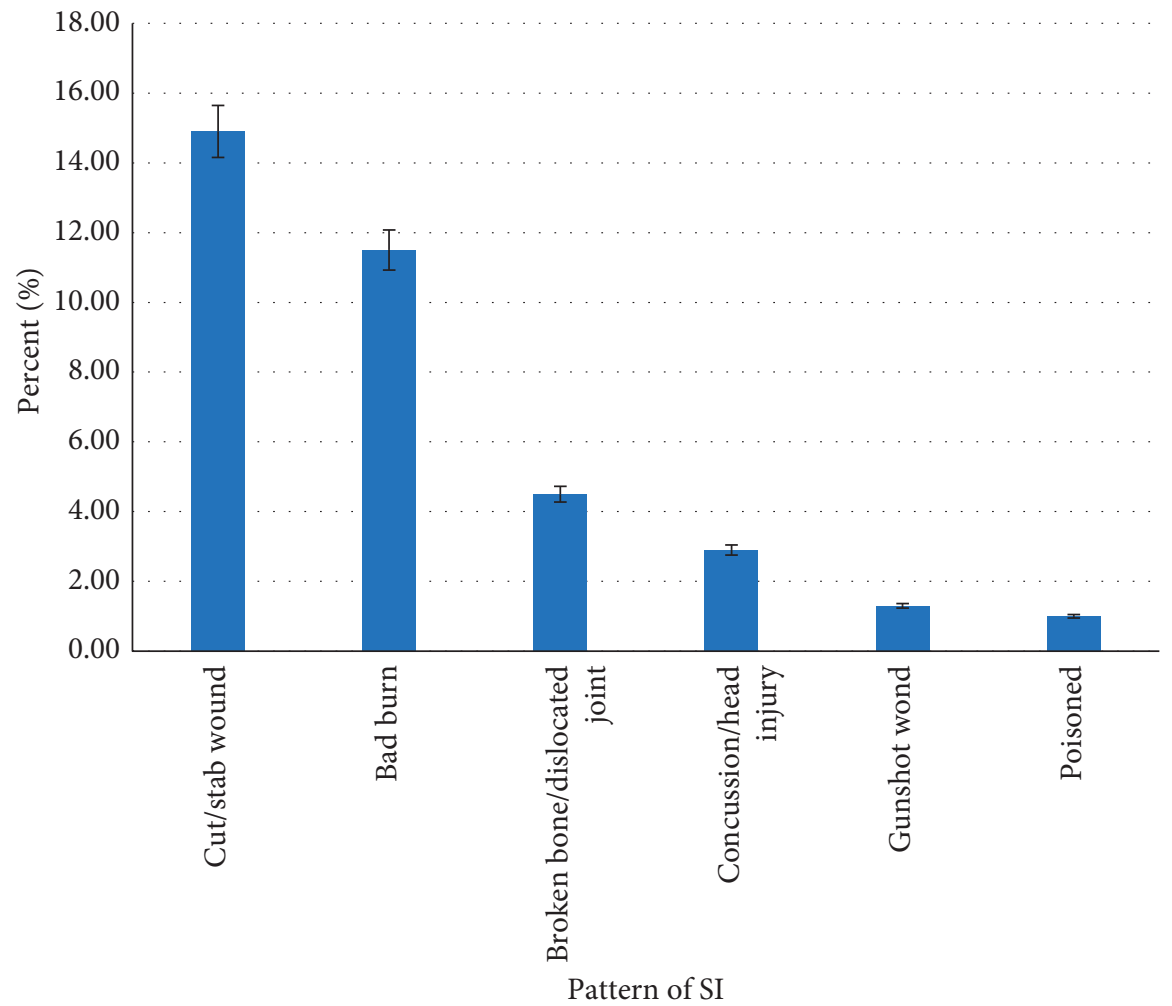

Figure 2: Pattern of serious injuries among adolescents in Ghana.

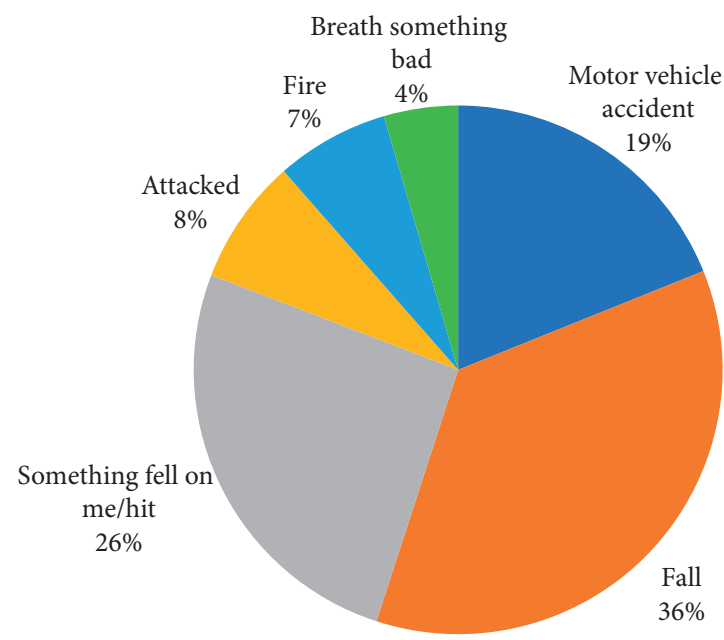

Figure 3: Cause of serious injuries among adolescents in Ghana.

institutions in Ghana are in a "boarding-house", hence the students' mobility is partly confined and regulated by the school authorities relative to junior high school students in the country. Likewise, SHS students' exposures to previous injuries might be influencing their current risky behaviors compared with JHS students.

Similar to prior studies, the survey found an association between psychological variables such as suicidal attempts and suicidal ideation [9, 21, 24], school truancy [24], and injuries. Therapy services in the high schools should be strengthened and be able to recognize these children in psychological distress and give their full support. In addition, parents need a close relationship with their children so that they can help their children overcome their psychological problems.

In this study, amphetamine use was independently associated with one or multiple injuries. These findings corroborate $[9,24]$. A holistic public health strategy is an effective way to tackle substance usage in a school setting which should be enhanced. This can be done through education, preventive health services, social support, and healthy physical environment and establish connections with the wider community.

The current study found an association between smoking marijuana and SI. This is consistent with a previous study of Adolescent Health and Lifestyle Survey (AHLS) among 8219 
TAвLE 3: Distribution of serious injuries across demographic, psychological, and personal attribute factors.

\begin{tabular}{|c|c|c|c|c|c|}
\hline & & & ury & & \\
\hline & & Injury (\%) & No injury (\%) & Chi-square & $p$ value \\
\hline Demographic facto & & & & & \\
\hline Sex & Male & $1013(51.3)$ & $881(48.7)$ & 0.704 & 0.405 \\
\hline & Female & $632(52.9)$ & $505(47.1)$ & & \\
\hline Educational level & JHS & $973(72.7)$ & $369(27.3)$ & 91.077 & $0.001^{*}$ \\
\hline & SHS & $938(55.9)$ & $770(44.1)$ & & \\
\hline & $12-14$ & $500(70.8)$ & $206(29.2)$ & 54.100 & $0.000^{*}$ \\
\hline Age (years) & $15-17$ & $855(64.8)$ & $465(35.2)$ & & \\
\hline & $\geq 18$ & $553(56.5)$ & $468(43.5)$ & & \\
\hline Number of close & & & & & \\
\hline & None & $217(60.3)$ & $164(39.7)$ & 6.0147 & $0.013^{*}$ \\
\hline & $\geq 1$ & $1672(66.7)$ & $971(33.3)$ & & \\
\hline Hunger (economi & & & & & \\
\hline & Low & $312(75.0)$ & $119(25.0)$ & 18.2257 & $0.006^{*}$ \\
\hline & High & $1602(64.7)$ & $1,019(35.3)$ & & \\
\hline Psychological facto & & & & & \\
\hline Suicidal ideation & Yes & $450(80.4)$ & $118(19.6)$ & 70.4520 & $0.000^{*}$ \\
\hline suicidal ideation & No & $1439(62.2)$ & $1023(37.8)$ & & \\
\hline & Yes & $500(75.5)$ & $175(24.5)$ & 39.9194 & $0.000^{*}$ \\
\hline Suicidal planning & No & $1355(62.5)$ & $956(37.5)$ & & \\
\hline Suicidal attempt & & & & & \\
\hline & Yes & $612(81.9)$ & $150(18.9)$ & 126.0745 & $0.000^{*}$ \\
\hline & No & $1280(60.1)$ & $956(39.9)$ & & \\
\hline Personal attributes & & & & & \\
\hline Truancy & Yes & $797(75.4)$ & $308(24.6)$ & 74.432 & $0.000^{*}$ \\
\hline Iruancy & No & $1095(60.2)$ & $822(39.8)$ & & \\
\hline Amphetamine use & & & & & \\
\hline & Yes & $176(92.2)$ & $18(7.8)$ & 82.2795 & $0.000^{*}$ \\
\hline & No & $1559(62.2)$ & $1072(37.8)$ & & \\
\hline Current drinker & & & & & \\
\hline & Yes & $304(80.9)$ & $86(119.1)$ & 50.0614 & $0.000^{*}$ \\
\hline & No & $1451(62.9)$ & $993(37.1)$ & & \\
\hline Current smoker & & & & & \\
\hline & Yes & $139(93.7)$ & $11(6.3)$ & 68.989 & $0.000^{*}$ \\
\hline & No & $1672(63.3)$ & $1109(36.7)$ & & \\
\hline
\end{tabular}

${ }^{*}$ Significant at $p<0.05$.

TABLE 4: Association between the significant variables and serious injuries.

\begin{tabular}{|c|c|c|c|c|}
\hline Variables & Unadjusted OR 95\% & $p$ value & Adjusted OR 95\% & $p$ value \\
\hline \multicolumn{5}{|l|}{ Sex } \\
\hline Male & Ref. & & Ref. & \\
\hline Female & $1.07[0.91-1.25]$ & 0.405 & $1.17[0.95-1.46]$ & 0.130 \\
\hline \multicolumn{5}{|l|}{ Educational level } \\
\hline SHS & $0.48[0.35-0.65]$ & 0.000 & $0.64[0.44-0.90]$ & 0.015 \\
\hline \multicolumn{5}{|l|}{ Age (year) } \\
\hline $12-14$ & Ref. & & Ref. & \\
\hline $15-17$ & $0.83[0.65-1.08]$ & 0.161 & $1.13[0.81-1.58]$ & 0.454 \\
\hline 18 and above & $0.51[0.39-0.66]$ & 0.000 & $0.73[0.52-1.02]$ & 0.305 \\
\hline \multicolumn{5}{|l|}{ Hunger } \\
\hline No & Ref. & & & \\
\hline Yes & 1.64 [1.17-2.33] & 0.007 & $1.37[1.00-1.89]$ & 0.045 \\
\hline \multicolumn{5}{|l|}{ Close friends } \\
\hline 0 & Ref. & & Ref. & \\
\hline$\geq 1$ & $1.32[1.07-1.63]$ & 0.013 & 1.49 [1.17-1.89] & 0.002 \\
\hline
\end{tabular}


TABLE 4: Continued.

\begin{tabular}{|c|c|c|c|c|}
\hline Variables & Unadjusted OR 95\% & $p$ value & Adjusted OR 95\% & $p$ value \\
\hline $\begin{array}{l}\text { Suicidal ideation } \\
\text { No } \\
\text { Yes }\end{array}$ & $\begin{array}{c}\text { Ref. } \\
2.5[1.89-3.33]\end{array}$ & 0.000 & $\begin{array}{c}\text { Ref. } \\
1.58[1.00-2.48]\end{array}$ & 0.05 \\
\hline $\begin{array}{l}\text { Suicidal planning } \\
\text { No } \\
\text { Yes }\end{array}$ & $\begin{array}{c}\text { Ref. } \\
1.85[1.44-2.38]\end{array}$ & 0.00 & $\begin{array}{c}\text { Ref. } \\
1.02[0.75-1.56] \\
\end{array}$ & 0.620 \\
\hline $\begin{array}{l}\text { Suicidal attempt } \\
\text { No } \\
\text { Yes }\end{array}$ & $\begin{array}{c}\text { Ref. } \\
3.03[2.17-4.17 \\
\end{array}$ & 0.000 & $\begin{array}{c}\text { Ref. } \\
1.88[1.29-2.72] \\
\end{array}$ & 0.001 \\
\hline $\begin{array}{l}\text { Truancy } \\
\text { No } \\
\text { Yes }\end{array}$ & $\begin{array}{c}\text { Ref. } \\
2.03[1.69-2.44]\end{array}$ & 0.000 & $\begin{array}{c}\text { Ref. } \\
1.66[1.31-2.09] \\
\end{array}$ & 0.000 \\
\hline $\begin{array}{l}\text { Amphetamine } \\
\text { No } \\
\text { Yes }\end{array}$ & $\begin{array}{c}\text { Ref. } \\
7.14[4.17-12.50]\end{array}$ & 0.000 & $\begin{array}{c}\text { Ref. } \\
2.95[1.46-5.95] \\
\end{array}$ & 0.004 \\
\hline $\begin{array}{l}\text { Current drinker (alcohol) } \\
\text { No } \\
\text { Yes }\end{array}$ & $\begin{array}{c}\text { Ref. } \\
2.50[1.72-3.57]\end{array}$ & 0.000 & $\begin{array}{c}\text { Ref. } \\
1.19[0.84-1.69]\end{array}$ & 0.316 \\
\hline $\begin{array}{l}\text { Current smoker } \\
\text { No } \\
\text { Yes }\end{array}$ & $\begin{array}{c}\text { Ref. } \\
8.68[4.54-16.67]\end{array}$ & 0.000 & $\begin{array}{c}\text { Ref. } \\
2.64[1.22-5.69]\end{array}$ & 0.015 \\
\hline
\end{tabular}

* Significant at $p<0.05 ; \mathrm{AOR}=$ adjusted for all factors which appear in table; goodness of fit $=F(9,17)=0.51 ; p=0.8495$.

adolescents aged 12-18 years [29] and study by Choi et al. [30] in South Korean. In the same vein, a dose-response association was shown between smoking and injury, with the risk of injuries greater than that of nonsmokers by $27 \%$ for low-level smokers, $37 \%$ for moderate smokers, and $71 \%$ for high-level smokers in the United States [31].

\section{Conclusion}

The findings of the study established a high prevalence of SI among adolescents in Ghana, with cut/stab wounds and broken/dislocated bone being the most reported type of injuries. This study also revealed that factors such as educational level, suicidal ideation, suicidal attempt, having at least one close friend, school truancy, smoking marijuana, and amphetamine use are associated with SI among the adolescents. Therefore, pragmatic interventional programs should be targeted at these factors to curb the rate of SI among adolescents in Ghana.

\section{Data Availability}

Data for this study were sourced from WHO Global School Health Survey and are available at http://www.who.int/chp/ gshs/en/.

\section{Additional Points}

Strengths and Limitations of the Study. This study is from a representative sample data from the 2012 Global SchoolBased Student Health Survey (GSHS) and makes room for generalizability of study findings across Ghana. Also, observations with complete dataset meeting the study criteria were large. However, data/information was obtained from a cross-sectional study design, limiting inferences of causations. Furthermore, data were obtained retrospectively, introducing a high recall bias since participants self-reported. Recall bias has significant effect on coefficient estimates and overall significant testing; therefore, interpretations/use of the findings should be done cautiously. Also, strength of the approach thus employed logistic regression as a result of the dichotomous nature of the recategorized dependent variable, which poses a limitation to this current study. We recommend future studies could employ robust precise informing analysis such as count analysis of serious injuries (Poisson analysis to provide more precise risk ratios) without recategorization of the outcome variable. In addition, several factors such as hunger were estimated based on proxy measures, which limits general extrapolations of study findings.

\section{Conflicts of Interest}

The authors declare that there are no conflicts of interest.

\section{Authors' Contributions}

MA conducted a literature search, planned the study, carried out data extraction, performed data analysis and interpretation, and drafted the manuscript. MGS carried out data extraction, performed data analysis, and interpretation. HB conducted a literature search and planned the study. All authors read and approved the final manuscript.

\section{Acknowledgments}

The authors are grateful to the WHO for making the data available for analysis. 


\section{References}

[1] C. Jildeh, Z. Abdeen, H. Al Sabbah, and A. Philalithis, "Unintentional injuries among school-aged children in Palestine: findings from the national study of Palestinian schoolchildren (HBSC-WBG2006)," International Journal of Population Research, vol. 2013, Article ID 629159, 7 pages, 2013.

[2] R. Lozano, M. Naghavi, K. Foreman et al., "Global and regional mortality from 235 causes of death for 20 age groups in 1990 and 2010: a systematic analysis for the Global Burden of Disease Study 2010," Lancet (London, England), vol. 380, no. 9859, pp. 2095-2128, 2012.

[3] D. Y. Melesse, M. K. Mutua, A. Choudhury et al., "Adolescent sexual and reproductive health in sub-Saharan Africa: who is left behind?" BMJ Global Health, vol. 5, no. 1, 8 pages, Article ID e002231, 2020.

[4] M. Ruiz-Casares, "Unintentional childhood injuries in SubSaharan Africa: an overview of risk and protective factors," Journal of Health Care for the Poor and Underserved, vol. 20, no. 4, pp. 51-67, 2009.

[5] B. T. Tiruneh, B. B. Bifftu, D. Z. Anlay, Y. S. Yismaw, E. Tesfaye, and B. A. Dachew, "Factors associated with unintentional injury among the paediatric age population in the hospitals of Amhara National Regional State, Ethiopia," African Journal of Emergency Medicine, vol. 7, pp. S55-S59, 2017.

[6] A. A. Hyder, M. Peden, and E. Krug, "Child health must include injury prevention," The Lancet, vol. 373, no. 9658, pp. 102-103, 2009.

[7] K. M. Keyes, E. Susser, D. J. Pilowsky et al., "The health consequences of child mental health problems and parenting styles: unintentional injuries among European schoolchildren," Preventive Medicine, vol. 67, pp. 182-188, 2014.

[8] S. J. Gilbride, C. Wild, D. R. Wilson, L. W. Svenson, and D. W. Spady, "Socio-economic status and types of childhood injury in Alberta: a population based study," BMC Pediatrics, vol. 6, no. 1, pp. 1-10, 2006.

[9] C. Gao, P. Chai, J. Lu, H. Wang, L. Li, and X. Zhou, "Probing the psychosocial correlates of unintentional injuries among grade-school children: a comparison of urban and migrant students in China," Journal of Child and Family Studies, vol. 28, no. 6, pp. 1713-1723, 2019.

[10] S. Azubuike and E. Onyemaka, "Epidemiology of non-fatal injuries among adolescents in an urban Niger delta community of Nigeria," International Journal of Critical Illness and Injury Science, vol. 2, no. 3, p. 180, 2012.

[11] A. Gyedu, E. K. Nakua, E. Otupiri, C. Mock, P. Donkor, and B. Ebel, "Incidence characteristics and risk factors for household and neighborhood injury among young children in semi-urban Ghana: a population-based household survey," HHS Public Access, vol. 21, pp. 1-23, 2016.

[12] K. J. Phelan, J. Khoury, H. Kalkwarf, and B. Lanphear, "Residential injuries in U.S. children and adolescents," Public Health Reports, vol. 120, no. 1, pp. 63-70, 2005.

[13] WHO, Global School-Based Student Health Survey (GSHS), WHO, Geneva, Switzerland, 2012, http://www.who.int/chp/ gshs/en/.

[14] J. R. Randall, D. Doku, M. L. Wilson, and K. Peltzer, "Suicidal behaviour and related risk factors among school-aged youth in the republic of Benin," PLoS One, vol. 9, no. 2, pp. e88233-e88239, 2014.

[15] K. Oppong Asante, "Cannabis and amphetamine use and its psychosocial correlates among school-going adolescents in
Ghana," Child and Adolescent Psychiatry and Mental Health, vol. 13, no. 1, pp. 1-9, 2019.

[16] K. Oppong Asante, N. Kugbey, J. Osafo, E. N.-B. Quarshie, and J. O. Sarfo, "The prevalence and correlates of suicidal behaviours (ideation, plan and attempt) among adolescents in senior high schools in Ghana," SSM-Population Health, vol. 3, pp. 427-434, 2017.

[17] D. B. Rubin, "Multiple imputation after 18+ years," Journal of the American Statistical Association, vol. 91, no. 434, pp. 473-489, 1996.

[18] K. J. Archer and S. Lemeshow, "Goodness-of-fit test for a logistic regression model fitted using survey sample data," The Stata Journal: Promoting Communications on Statistics and Stata, vol. 6, no. 1, pp. 97-105, 2006.

[19] S. Pengpid, J. T. Hinneh, and K. Peltzer, "Prevalence and correlates of single and multiple unintentional non-fatal injuries among school-going adolescents in Liberia," Injury, vol. 20-1383, no. 20, pp. 30973-30976, 2020.

[20] R. A. Salam, A. Arshad, J. K. Das et al., "Interventions to prevent unintentional injuries among adolescents: a systematic review and meta-analysis," Journal of Adolescent Health, vol. 59, no. 4, pp. S76-S87, 2016.

[21] K. Peltzer and S. Pengpid, "Injury and social correlates among in-school adolescents in four Southeast Asian countries," International Journal of Environmental Research and Public Health, vol. 9, no. 8, pp. 2851-2862, 2012.

[22] K. Poudel-Tandukar, S. Nakahara, M. Ichikawa, K. C. Poudel, A. B. Joshi, and S. Wakai, "Unintentional injuries among school adolescents in Kathmandu, Nepal: a descriptive study," Public Health, vol. 120, no. 7, pp. 641-649, 2006.

[23] A. Alshahethi, A. A. Serouri, and Y. S. Khader, "Rate and pattern of unintentional injuries among 9-12 grades schoolchildren in Yemen and their associated factors," Journal of Injury \& Violence Research, vol. 10, no. 2, pp. 75-82, 2018.

[24] S. Pengpid and K. Peltzer, "Unintentional injuries and sociopsychological correlates among school-going adolescents in Mozambique," Vulnerable Children and Youth Studies, vol. 15, no. 1, pp. 32-39, 2019.

[25] F. A. Abantanga and C. N. Mock, "Childhood injuries in an urban area of Ghana a hospital-based study of 677 cases," Pediatric Surgery International, vol. 13, no. 7, pp. 515-518, 1998.

[26] A. Rommel, G. Varnaccia, and A. C. Saß, "Unintentional injuries and gender-using CRT to identify specific injury profiles for men and women," European Journal of Public Health, vol. 23, p. 26000, 2013.

[27] K. Peltzer and S. Pengpid, "Unintentional injuries and psychosocial correlates among in-school adolescents in Malaysia," International Journal of Environmental Research and Public Health, vol. 12, no. 11, pp. 14936-14947, 2015.

[28] K. Simpson, I. Janssen, W. M. Craig, and W. Pickett, "Multilevel analysis of associations between socioeconomic status and injury among Canadian adolescents," Journal of Epidemiology \& Community Health, vol. 59, no. 12, pp. 1072-1077, 2005.

[29] V. Mattila, J. Parkkari, P. Kannus, and A. Rimpelä, "Occurrence and risk factors of unintentional injuries among 12- to 18-year-old Finns-a survey of 8219 adolescents," European Journal of Epidemiology, vol. 19, no. 5, pp. 437-444, 2003.

[30] K.-C. Choi, S. A. Kim, N. R. Kim, and M.-H. Shin, "Association between smoking and unintentional injuries among Korean adults," Chonnam Medical Journal, vol. 54, no. 3, pp. 184-189, 2018. 
[31] S. A. Bedno, R. Jackson, X. Feng, I. L. Walton, M. R. Boivin, and D. N. Cowan, "Meta-analysis of cigarette smoking and musculoskeletal injuries in military training," Medicine \& Science in Sports \& Exercise, vol. 49, no. 11, pp. 2191-2197, 2017. 